\title{
Forming Interrogation of Rolling Process using Rollers
}

\author{
D.Muruganandam, J.Jayapriya, B.Ramesh, S.Suraj
}

\begin{abstract}
In this article to be created three dimensional model of reinforced plastic using finite element analysis (FEA) to simulated slab rolling between rollers by wide thickness in work piece is analyzed. The behaviour of materials while rolling roller at the time of pass, finite element deform $3 d$ program employed and developed $3 D$ model of the heat developed rolling process.

The influences of different process parameters namely speed of the roller, thickness of the slab, thickness reduction \& heat transfer coefficient are taken an account. The stress, strain \& strain rate, the temperature distribution in the roll and the slab, are developed throughout a steady-state analysis of the process involved. From the simulation process, the machining possibilities are obtained
\end{abstract}

\section{INTRODUCTION}

In manufacturing companies, the rolling process is very important and familiar process in almost $80 \%$ to $85 \%$ of metallic equipment has been developed to rolling. The most kinds of the rolling processes and most practical one is flat rolling.

Rolling process is used to reduce the thickness of the workpiece, from initial thickness to predetermined final thickness. When the rollers are rotating at a constant angular velocity, the slab is moved between the roller and it is subjected to high compressive stress as a result to deformation due to the friction forces exerted by the rollers.

The interface of the slab and rolls, the rolling load can be reduced by improving the rolling conditions and quality of the surface can be improved significantly. Temperature of the slab and coefficient of friction and the strain rate was generally strongly considered and based on process and material specifications depending upon adhesion hypothesis of hot rollers

The most difficult metal-forming processes are rolling, because the rolling process quasi-static/even dynamic \& inelastic, Work piece undergoes large strains and thus has latest new relations; and the rolling process involves complicated friction, thermo-mechanical coupling, and undesirable mechanical vibrations is created while rolling process.In this rolling process aluminium slab is used as work piece. The purpose of choosing aluminium is that it has low melting point so that it can be easily deformed.

The second most broadly used in the world is ferrous based hardened metal after iron and aluminium. Aluminium has properties like malleability, easy machining, less weight,

Revised Manuscript Received on August 05, 2019.

D.Muruganandam, Professor, Department of Mechanical Engineering, Sri Venkateswaraa College of Technology, Chennai, Tamilnadu, India.

J.Jayapriya, Assistant Professor, Department of Mathematics, Sathyabama Institute of Science and Technology, Chennai, Tamilnadu, India.

B.Ramesh, Professor, Department of Mechanical Engineering, Sri Muthu Kumaran Institute of Technology, Chennai, Tamilnadu, India.

S.Suraj, Graduate -Electrical Engineering, New Jersey Institute of Technology, USA. more strength, excellent corrosion resistance and good thermal and electrical conductivity.

EN24 metal is important grade of through-hardening alloy steel due to its excellent machinability and further surface-hardened to develop components. It is used in components such as studs and bolts, gears \&shafts etc.,

The values are tensile strength- 850 to $1000 \mathrm{~N} / \mathrm{mm}^{2}$ and yield stress- $680 \mathrm{~N} / \mathrm{mm}^{2}$ (minimum).

\section{LITERATURE SURVEY}

A.R. Shahani et al (2009)[1],discussed the temperature distribution in the roll and the slab, the stress, strain and strain rate fields. Further, studying the flat hot rolling by using a developed rigid-viscoplastic finite element analysis has been investigated by Chunhui luo et al (2001)[2]. The conventional analysis has been converged by simulating a $3 \mathrm{~d}$ metal rolling process with the use of different frictional shear stress models, mesh division and number of elements in deformation zone by z.y.jiang et al (2001)[3]

In addition, Zone-Ching Lin et al (2001)[4] improved a finite element model to develop a heat transfer finite element model. Simulating vertical-horizontal rolling process during width reduction in the roughing stands of a hot slab mill by Xiong Shangwu et al (2000)[5], attracted the attention of Minting Wang (2004) et al [6] that leads to development of mechanical behaviour \& the dynamic structure changes.

Cheng Gang Sun et al (2005) [7], Investigated of interfacial behaviour between the slab and roll in hot slab rolling by finite element analysis and Mahdi Bagheripoor et al (2013)[8],developed an artificial neural network (ANN) application to a hot slab mill to increase the model's identify for rolling force \& rolling torque, as a function of lot of process parameters. The above Investigation by the various researchers give ample evidence of existence of innovation in the domain of Rolling process.

\section{MODELING AND ANALYSIS}

Using finite element software package created 3D rolling model and simulate a one move of the hot rolling process for aluminium. DEFORM 3D 


\section{Forming Interrogation of Rolling Process using Rollers}

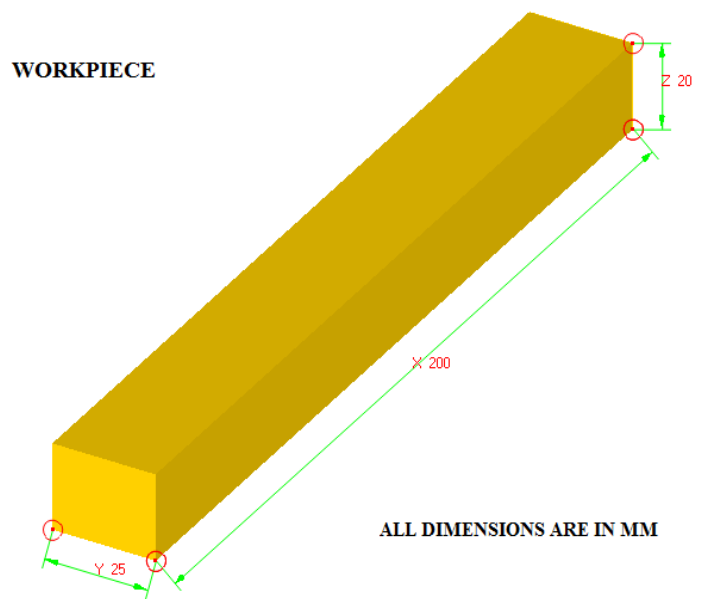

ROLLER
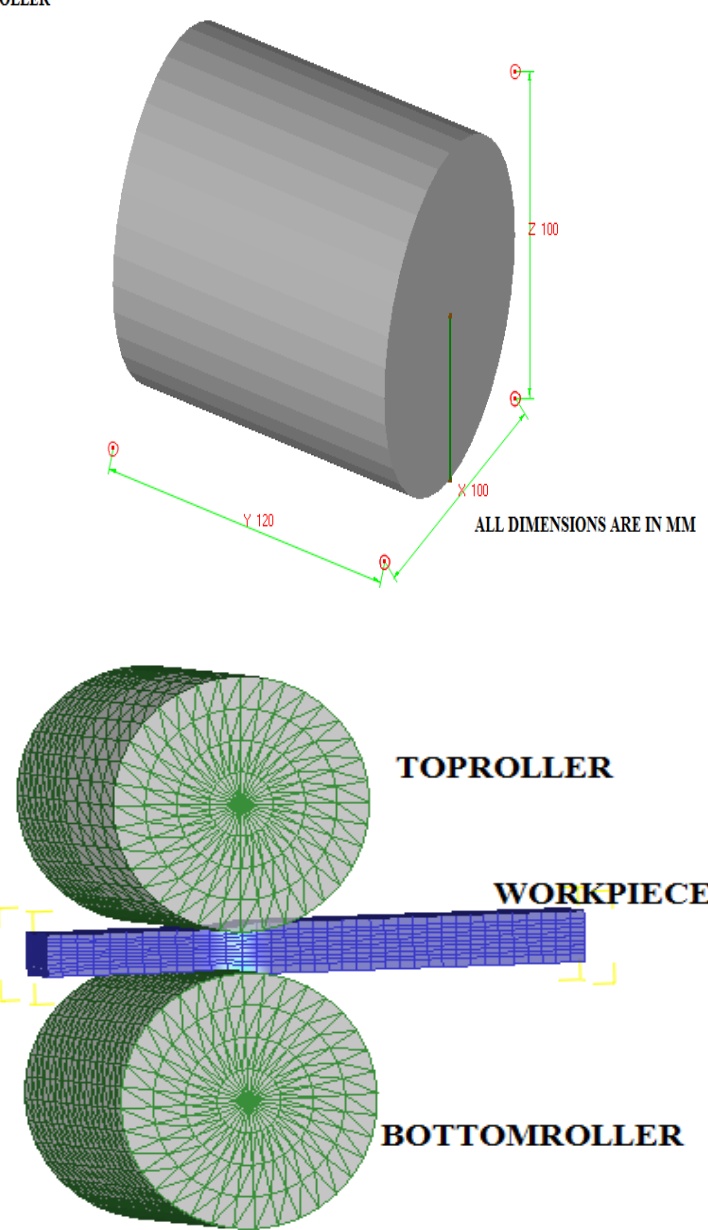

In this simulation the initial condition for the slab breadth is $25 \mathrm{~mm}$, thickness is $20 \mathrm{~mm}$, length is $300 \mathrm{~mm}$, temperature is $300^{\circ} \mathrm{c}$ and the roller diameter is $100 \mathrm{~mm}$, thickness is 120 $\mathrm{mm}$ and speed is $100 \mathrm{rpm}$. Since there is change in width, the vertical compression of the material directional is translated in to elongation in the rolling direction.Frictional force is needed to pull the metal into roll and responsible for larger portion of rolling load.At the end of deformation, the slab thickness is reduced to $14 \mathrm{~mm}$ thickness, width is $27 \mathrm{~mm}$ and length is elongated to $383 \mathrm{~mm}$.

\section{MATHEMATICAL DISCUSSION}

The strain rates \& range of temperatures developed by the materials while the rolling process is high and the slab's plastic behaviour of both temperature and strain rate, hyperbolic sine equation used by Mahdi Bagheripoor et al [8].

$$
\dot{\varepsilon}=A \exp \left(\frac{-Q_{\text {def }}}{R \theta}\right)\left[\sinh \left(\xi \frac{\tilde{\sigma}}{s}\right)\right]^{\frac{1}{m}},
$$

where $\mathrm{A}, \mathrm{n}$ and $\mathrm{m}$ are material constants, $\dot{\mathcal{E}}$ is the mean equivalent plastic tensile strain rate, $\widetilde{\sigma}$ the equivalent tensile stress, Qdef the activation energy for deformation, R the universal gas constant, $h$ the absolute temperature and $s$ is a scalar internal variable with dimensions of stress and $\mathrm{A}$ $=1.91 \mathrm{E} 7$, Qdef $=175.3 \mathrm{~kJ} / \mathrm{mole}, \mathrm{n}=7$ and $\mathrm{m}=0.23348$ The above flow stress parameters have been referred from

\section{Mahdi Bagheripoor et al.}

\subsection{Coefficient Of Friction:}

Coefficient of the friction is given by,

$$
\mu=\tan \alpha
$$

where,

$\alpha$ is the coefficient of friction.

\subsection{Maximum Width Reduction:}

The basic formula on width reduction is given below,

Where,

$$
(\Delta h)_{\max }=\mu^{2} R
$$

$\mu$ is coefficient of friction.

$\mathrm{R}$ is radius of the roller.

\section{RESULTS AND DISCUSION}

\subsection{Effect Of Reduction:}

Between rollers increased reduction ratio it developed the separating force all so the same.

It leads to be the pass strain and develop of the contact area .The roller pressures also increased

Depending upon the reduction ratio will affect with influences the flow stress of slab. It rises and will affect the flow stress. Influences, not only improving the effective strain but also interaction between the temperature increases because of heat developed by plastic deformation.

\subsubsection{Effective strain:}

Depending upon status of the reduction roller ratio modify slab deformation, may increases both relatively. It may cause more plastic mobility in the slab and developing more strain. 


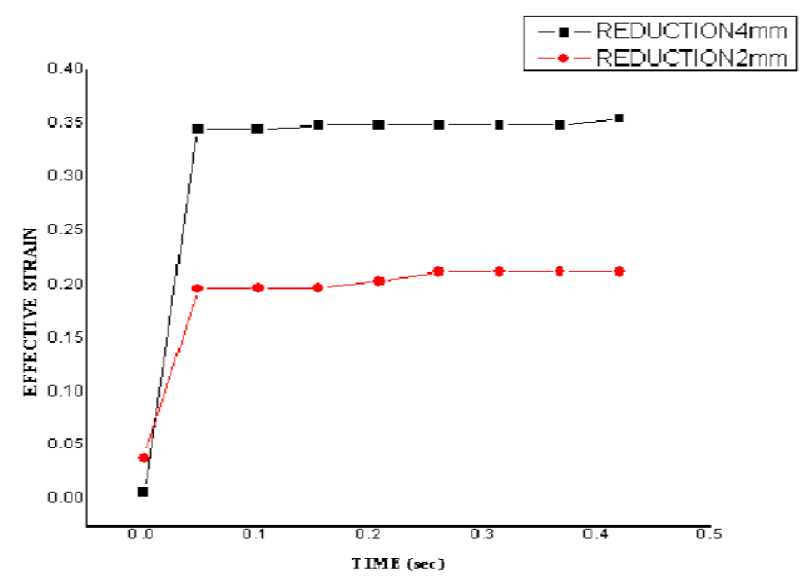

Figure 5.1(a)

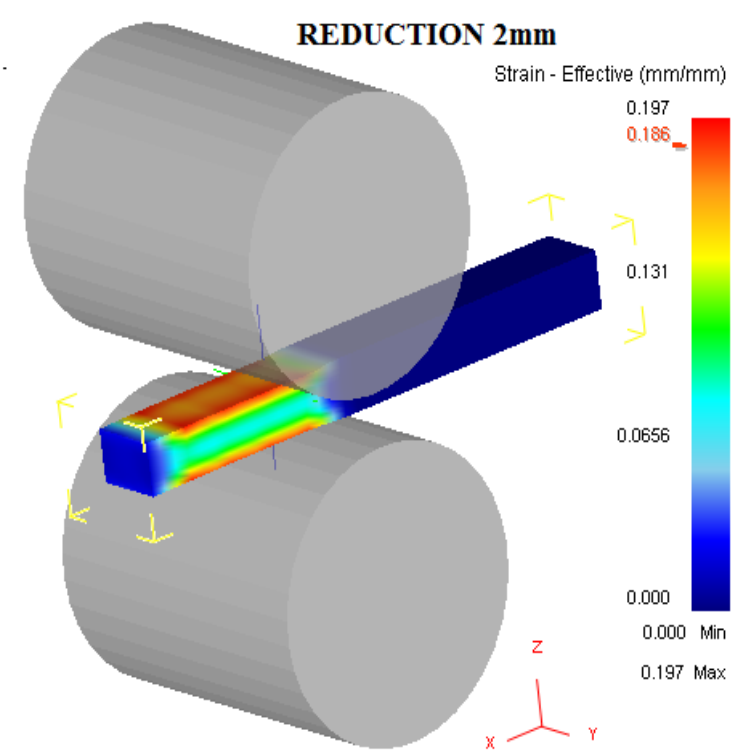

Figure. 5.2 (a)

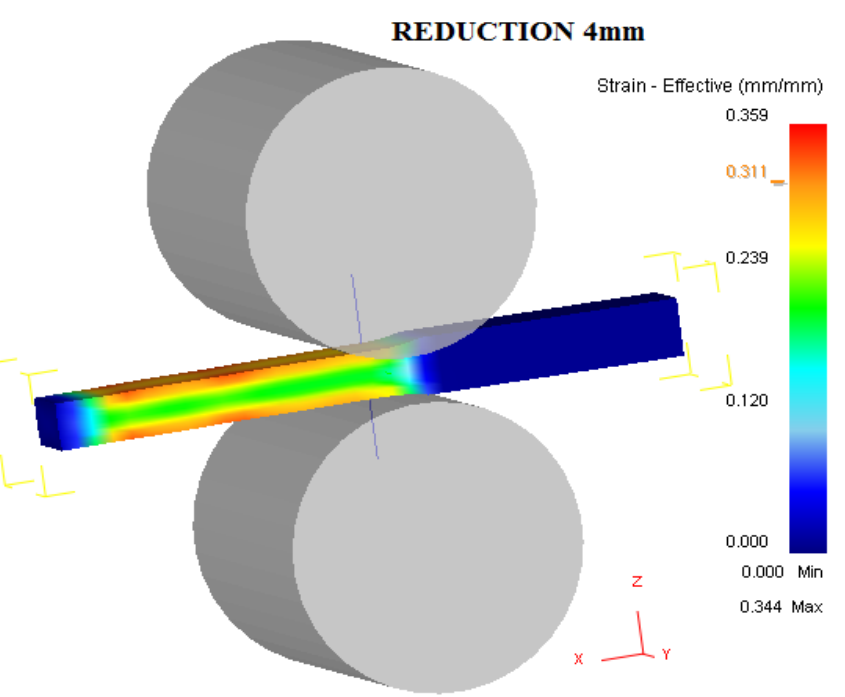

Figure.5.2 (b)

The effective strain increases due to the increase of reduction is shown in the figure.5.1 (a).For various reduction, the strain increases after the slab moved between rollers is shown in figure.5.2 (a\&b). The study in [ZoneChing Lin et al [4]] also finds this was true.

\subsubsection{Heat:}

Heat and friction leads depending upon the greater plastic deformation of slab under crushing between the rollers, Due to that more reduction of the slab taken place. Higher temperature rise the higher reduction of slab is shown in figure.5.3 (a\&b), Which is also verified in the study recorded in A.R. Shahani et al [1].

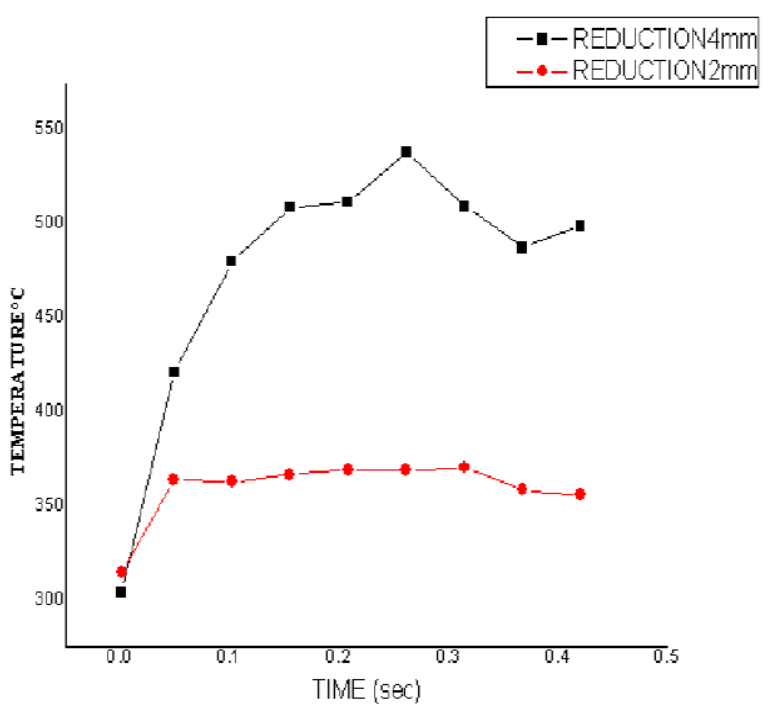

Figure.5.3(a)

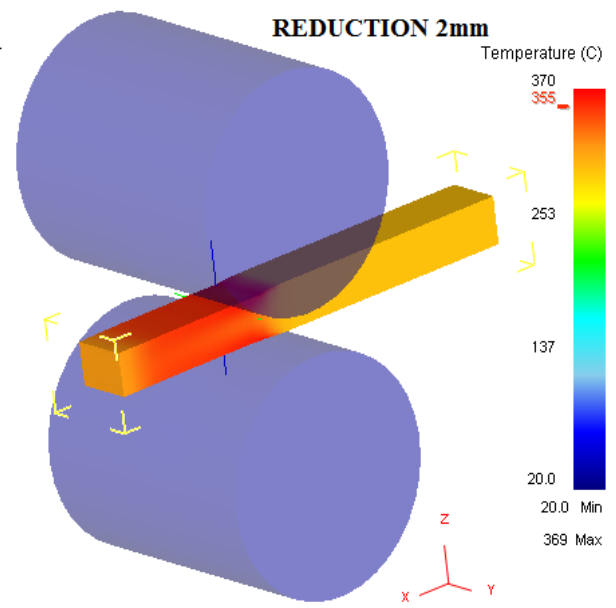

Figure.5.3(b)

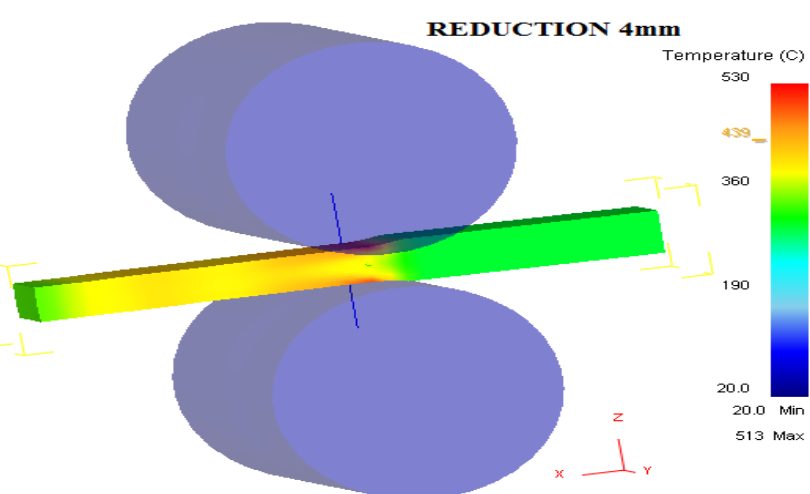

Figure.5.4(a\&b)

Published By: 


\section{Forming Interrogation of Rolling Process using Rollers}

Figure.5.4(a\&b) shows temperature increases after the slab moved between the rollers for various reduction.

\subsection{Effects Of Speed:}

Depending upon the speed of the roller the strain of the rolled materials will be modifying. Here in result, the of the flow stress of slab with respect to high rolling speed.

Among contacting surfaces of roll \& slab the contact temperatures were developed.

Because of less contact time and high heat developed by the frictional force and higher relative velocity.

\subsubsection{Temperature:}

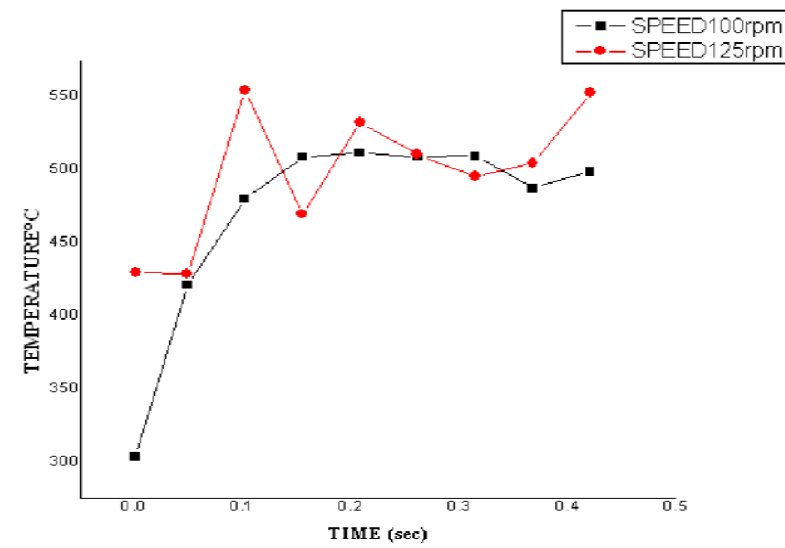

Figure.5.5

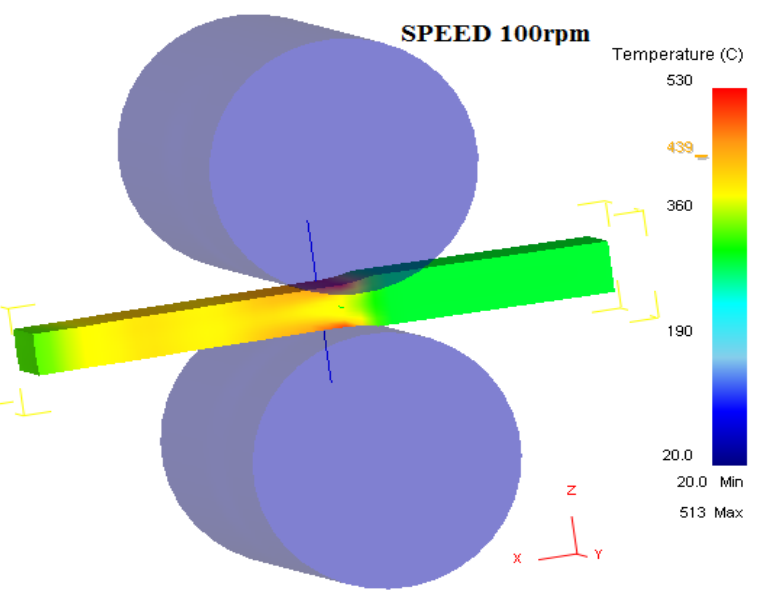

Figure.5.6(a)

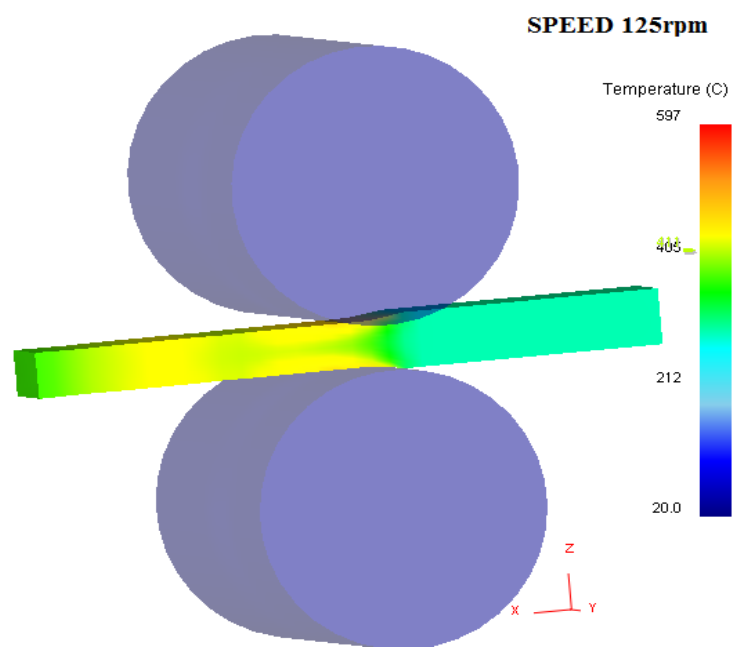

Figure.5.6(b)
From the figure5.5 shows the speed increases, temperature of the aluminum slab also increases. The plot [figure.5.6 (a\&b)] shows the temperature increases after the workpiece moved between rollers at various speed.

\subsubsection{Effectitive Strain:}

Due to the increase in temperature by increased speed, affects the flow stress. The effective strain was decreased.As illustrated by Cheng Gang Sun et al [7], increasing the speed will increase the temperature.

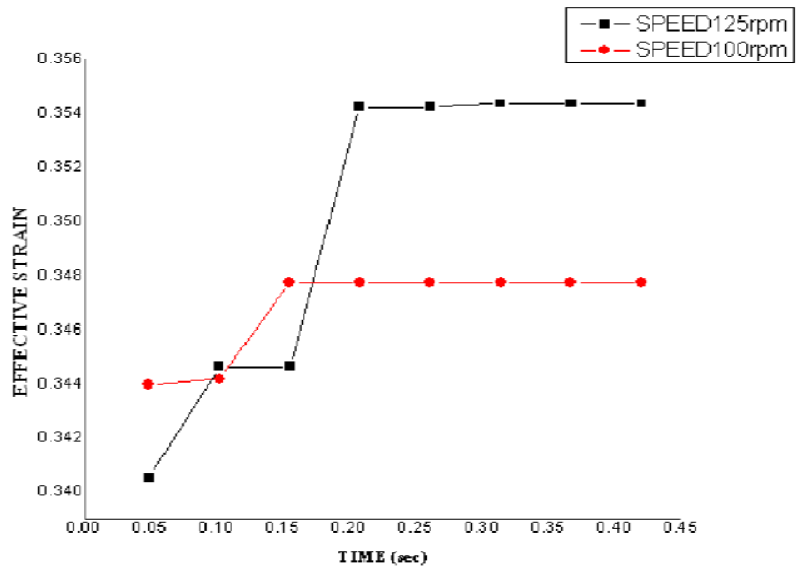

Figure.5.7

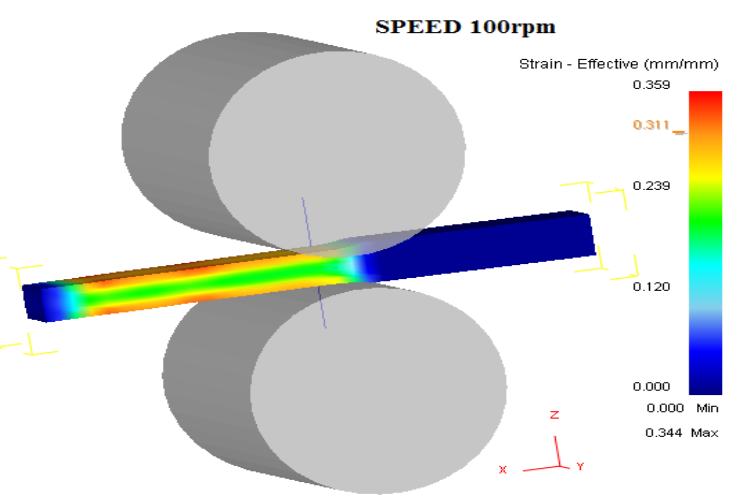

Figure.5.8(a)

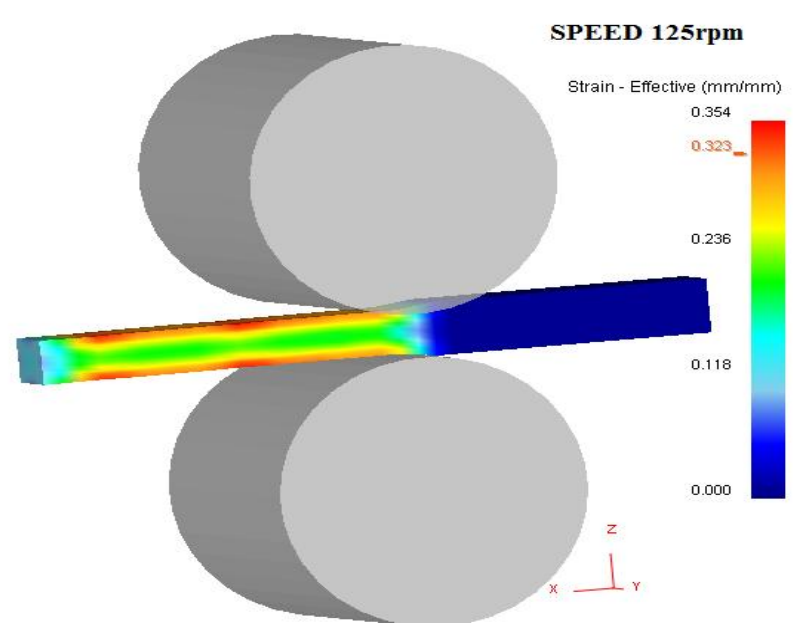

Figure.5.8 (b) 
The plot [figure.5.8 (a \& b)] show when the speed is increased, the effective strain is decreased.

\subsection{Effect Of Temperature:}

Due to thermal influences, developing the slab temperatures drastically decrease the flow stress of slab but decrease of rolling force.

Depending upon roller pressure may reduce the original area of the mating at the interface, showing frictional force and strain goes down

\subsubsection{Effective Strain:}

Simulations were carried out at two different temperatures. Figure.10 (a \& b) represents this comparison. Cheng Gang Sun et al [7] also stated that the increasing temperatures, decreases the effective strain and roll pressure.

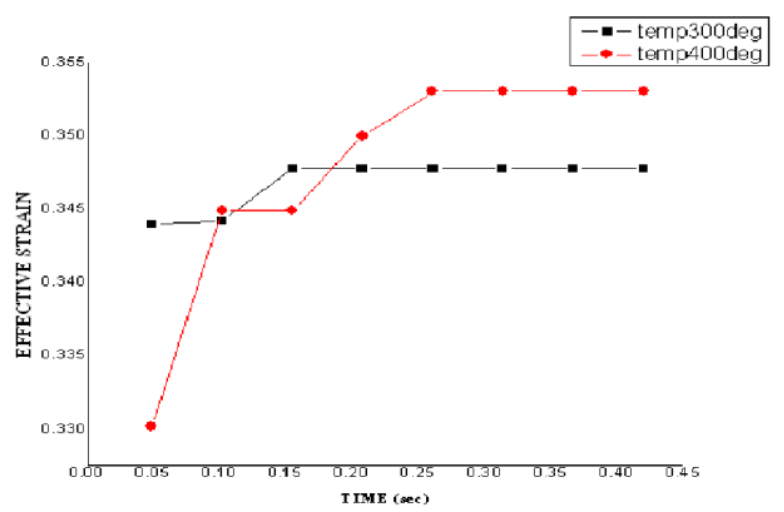

Fig.9

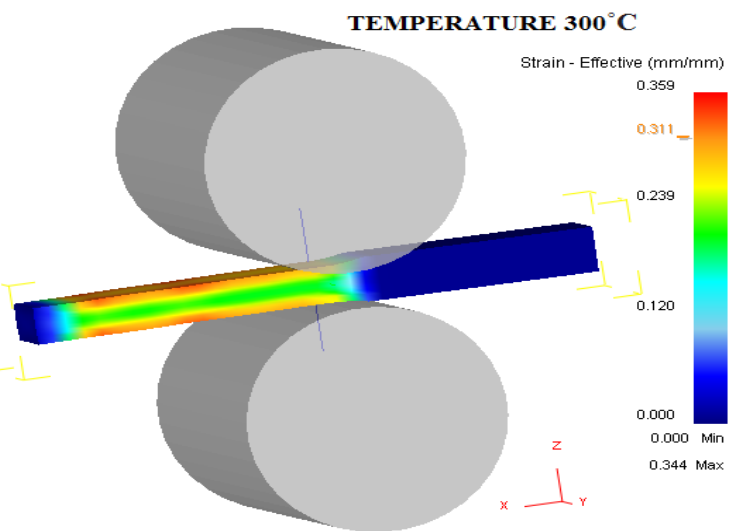

Figure.5.10 (a)

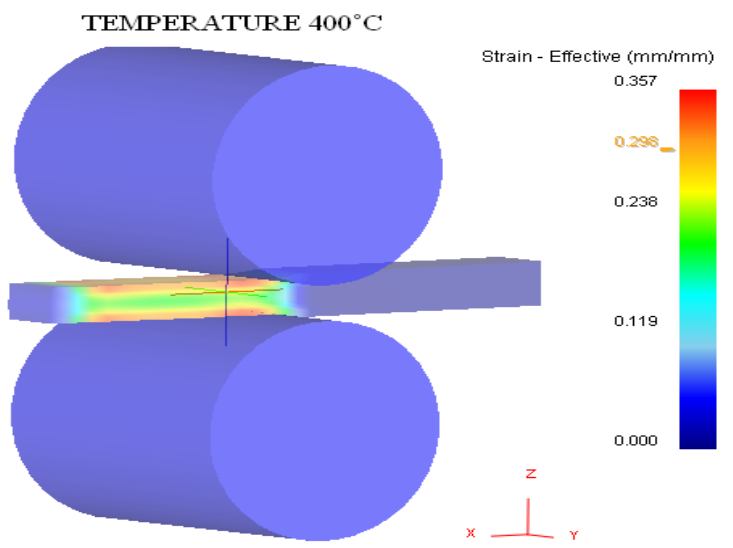

Figure.5.10 (b)
From the plot [figure.10 (a \& b)] the increase in temperature, causes decreases in the effective strain.

\section{CONCLUSION}

Developed 3D model of the slab and roller using finite element approach for the contacting leads thermal \& mechanical behaviour of the roll and slab in the hot rolling. The article simulated the hot rolling of aluminium slab under different reduction, different speed and temperature to shows the effects of the above parameters on hot rolling process.

Further concludes as follows:

- The strain rate, and develops greater effective strain and temperature rise due to high reduction increases the rolling force.

- Increasing rolling speed affects the strain rate and roll pressure but increases the temperature of the slab.

- $\quad$ The amount of initial temperature of work piece is another parameter, while Increasing the slab temperature, its leads to decreases pressure, and effective strain

\section{REFERENCES}

1 A. R. Shahani, Saeed Setayeshi, S. A. Nodamaie, M. A Asadi, 2009, Journal of materials processing technology, Prediction of influence parameters on the hot rolling process using finite element method and neural network, Vol. 209, Issue. 4, pp. 1920-1935.

2 Chunhui Luo, Ulf Ståhlberg, 2001, Journal of Materials Processing Technology, Deformation of inclusions during hot rolling of steels, Vol. 114, issue. 1, pp. 87-97.

3 Z. Y Jiang, A. K Tieu, 2001, Journal of Materials Processing Technology, A simulation of threedimensional metal rolling processes by rigid-plastic finite element method, Vol. 112, Issue. 1, pp. 144-151.

4 Zone-Ching Lin, Chi-Chih Shen, 2001, Journal of Materials Processing Technology, A coupled finite element method for a three-dimensional analysis of the flat rolling of aluminum with different reductions, Vol. 110, Issue. 1, pp. 10-18.

5 Shangwu Xiong, Xianghua Liu, Wang Guodong, Zhang Qiang, 2000, Journal of Materials Processing Technology, Three-dimensional finite element simulation of the vertical-horizontal rolling process in the width reduction of slab, Vol. 101, Issue. 1, pp. 146-151.

6 Minting Wang, Xuetong Li, Fengshan Du, Yangzeng Zheng, 2004, Materials Science and Engineering: A, Hot deformation of austenite and prediction of microstructure evolution of cross-wedge rolling, Vol. 379, Issue. 1-2, pp. 133-140.

7 Cheng-Gang Sun, Jong-Seog Lee, Jung-Hyeung Lee, Sang-Moo Hwang, 2005, ISIJ International, Mechanism of Edge Seam Defects of Stainless Steel Generated during Hot Plate Rolling, Vol. 46, Issue. 1, pp. 93-99. 